\title{
Panorama sobre la situación de los estudios de cine en Argentina a partir del año 2000
}

\author{
Lic. Alejandro Kelly Hopfenblatt
}

Becario doctoral. Universidad de Buenos Aires. Facultad de Filosofía y Letras. Instituto de Artes del Espectáculo - CONICET

E-mail: alejandro.kelly.h@gmail.com

ORCID iD: http://orcid.org/0000-0001-6951-5289.

Web: uba.academia.edu/AlejandroKellyHopfenblatt

\section{Resumen}

Durante la última década los estudios de cine en Argentina se han convertido en un campo de gran dinamismo, creciendo cuantitativa y cualitativamente. Su consolidación ha significado la producción de trabajos en torno a una amplia heterogeneidad de temáticas y perspectivas, fundada en el carácter interdisciplinar que ha caracterizado a esta tradición académica. Es el objetivo de este artículo brindar un panorama sobre la situación de los estudios de cine en Argentina a partir del año 2000. No aspiramos a un abordaje exhaustivo, sino que se busca dar cuenta de las dinámicas internas e interconectadas de un campo en constante reformulación. Para ello se han identificado en primer lugar las transformaciones del ámbito de la investigación que han posibilitado el afianzamiento de estos estudios. En este contexto se propone destacar los principales núcleos conceptuales y las líneas de investigación dominantes y recesivas que han dado forma a este campo. Se señalan en este sentido tanto aquellas líneas de trabajo que provienen de la tradición crítica como las que han surgido en sintonía con las transformaciones en la serie social, política y cultural. Asimismo, se propone indagar en las nuevas perspectivas emergentes que están cuestionando algunos conceptos fundamentales que han estructurado estas investigaciones, incluido el propio estatuto del cinematógrafo.

\section{Palabras clave}

Estudios de cine, Argentina, Siglo XXI,

\begin{abstract}
During the last decade, film studies in Argentina have become a strongly active field, growing both quantitatively and qualitatively. Its consolidation has meant the development of investigations that delve into a widely heterogeneous array of themes and perspectives, based on this area's characteristic interdisciplinarity. This paper aims to present an outlook to film studies in Argentina in the $21^{\text {st }}$ Century. It does not intend an exhaustive approach, whereas it shows the internal interconnected dynamics of this constantly rearranging field. In doing so, it identifies in the first place the academic and organizational changes that have made possible films studies' strengthening in Argentina. Considering this context, this paper presents the main concepts and both dominant and residual lines of research that have given shape to this field. Thus, it considers both those perspectives that come from critical traditions and those that originated and grew in line with social, political and cultural transformations. Likewise, this paper suggests looking into new emergent perspectives that are questioning some core concepts of film studies, including cinematography's own statute.
\end{abstract}

\section{Key Words}


Film Studies, Argentina, 21st Century

\section{Sumario}

1. Introducción. 2. Campo de posibilidades para la consolidación de los estudios de cine en Argentina. 2.1 Políticas editoriales. 2.2 Ámbitos de investigación. 2.3 Profesionalización del campo. 3. Los estudios de cine y el Nuevo Cine Argentino. 4. Documental, historia y memoria. 5. Cine y política. 6. Transitando la historia del cine. $6.1 \mathrm{El}$ cine silente. $6.2 \mathrm{El}$ cine clásico. 6.3 El cine moderno. 6.4 Otros ámbitos de la historia del cine. 7. Reflexiones teóricas sobre el cine. 8. Entre lo regional y lo trasnacional. 9. El cine en la era del audiovisual. 10. Bibliografía. 10.1 Bibliografía sobre Nuevo Cine Argentino. 10.2 Bibliografía sobre Documental, Memoria e Historia. 10.3 Bibliografía sobre Cine y Política. 10.4 Bibliografía sobre Historia del cine argentino. 10.5 Bibliografía sobre Reflexiones teóricas del cine. 10.6 Bibliografía sobre lo Regional y lo Trasnacional. 10.7 Bibliografía sobre el Audiovisual. 10.8 Bibliografía sobre los Estudios de Cine en Argentina. 10.9 Filmografía de Documentales sobre Cine. 11. Notas

\section{Summary}

1. Introduction. 2. Field of possibilities for the consolidation of Film Studies in Argentina. 2.1 Publishing politics. 2.2 Research facilities. 2.3 Field professionalization. 3. Film studies and New Argentine Cinema. 4. Documentary, history and memory. 5. Film and politics. 6. Travelling through film history. 6.1 Silent film. 6.2 Classical film. 6.3 Modern field. 6.4 Other areas of film history. 7. Film theory considerations. 8. From regional to transnational. 9. Film in the age of audiovisual. 10. Bibliography. 10.1 Bibliography on New Argentine Cinema. 10.2 Bibliography on Documentary, Memory and History. 10.3 Bibliography on Film and Politics. 10.4 Bibliography on Argentine Film History. 10.5 Bibliography on Film Theory. 10.6 Bibliography on Regional and Transnational. 10.7 Bibliography on Audiovisual. 10.8 Bibliography on Film Studies in Argentina. 10.9 Filmography on Film Documentaries. 11. Notes

\section{Introducción}

La primera década y media del siglo XXI han sido un periodo de intensa producción, complejización y diversificación para los estudios cinematográficos en Argentina. En estos años, este ámbito se ha consolidado, creciendo en términos cuantitativos y cualitativos. Los tiempos presentes encuentran así un campo efervescente, donde se continúan abriendo caminos de investigación y postulando miradas teóricas, metodológicas y analíticas novedosas.

El nuevo siglo fue escenario del afianzamiento y profesionalización de un campo de estudios que se venía formando desde algunas décadas anteriores. Según señala María Belén Ciancio (2013) en su investigación sobre la formación de los estudios de cine en Argentina, a partir de 1983, con la carrera de Artes de la Facultad de Filosofía y Letras de la Universidad de Buenos Aires, los estudios de cine comenzaron un camino hacia la autonomía. Este desarrollo no fue, sin embargo, hacia su conformación como una disciplina académica sino que se basó en el reconocimiento del carácter interdisciplinar de los estudios de cine. Destaca de este modo la preminencia en Argentina de tendencias como los Memory Studies, la Teoría Crítica, la Escuela de Frankfurt, los Estudios Culturales (con autores destacados como 
Raymond Williams y Frederic Jameson), las propuestas de Siegfried Kracauer y de Gilles Deleuze, los estudios de género y los Queer Studies.

El campo diverso y polifónico de los estudios de cine en Argentina se fue conformando gradualmente al mismo tiempo que se producían cambios sustantivos en la propia producción fílmica nacional a partir del surgimiento de lo que se denominó como Nuevo Cine Argentino a mediados de los años noventa. Al mismo tiempo, el terreno político del cambio de siglo con la crisis del 2001 y la reconsideración del pasado traumático reciente llevaron a un mayor interés por el rol del audiovisual en los procesos sociales y políticos. Es así que la renovación estética, narrativa y productiva de la cinematografía vernácula y el convulsionado terreno político y social generaron un campo de ebullición de problematizaciones y reformulaciones de interrogantes en torno al audiovisual.

Ciancio propone que los estudios de cine pasaron por un umbral de positividad donde se hacen presente la semiología y el estructuralismo, la historiografía, la sociología y los estudios culturales; y un umbral de epistemologización, donde la crítica vernácula pasó a reflexionar y teorizar el Nuevo Cine. Dentro de éste último destaca la aparición de dos publicaciones, Otros mundos: Un ensayo sobre el nuevo cine argentino (Aguilar, 2006) y La imagen justa (Amado, 2009), que postularon nuevas perspectivas del Nuevo Cine, la política y la memoria. Señala asimismo la publicación en esos años de los libros sobre cine documental de Josefina Sartora y Silvina Rival (2007) y de Javier Campo y Christian Dodaro (2007), que confirmaron el lugar fundamental que tendría esta cuestión en el desarrollo de los estudios de cine en Argentina.

Favorecidos por los incentivos a la investigación y el desarrollo de distintas instancias académicas de fomento e intercambio, los estudios de cine en Argentina se han consolidado como un campo dinámico. Ciancio destaca la primacía de las temáticas de la memoria, el género y el cuerpo como sus principales ejes vertebradores. A ellos se le pueden sumar otros conceptos que, desde miradas interdisciplinares, han suscitado gran cantidad de debates como la relación con lo político y con lo real, la historia de y en el cine y la propia definición del 'cine' frente a las transformaciones del audiovisual contemporáneo.

Este artículo se propone presentar un recorrido por los ejes fundamentales de los estudios de cine en Argentina en el siglo XXI. Sin ser un mapa exhaustivo, se plantearán los nudos centrales y los intereses dominantes del campo. Para ello, nos detendremos en un primer momento en una revisión del campo de posibilidades que ha llevado al desarrollo exponencial de estas investigaciones para luego abordar una serie de espacios que han articulado las principales discusiones. Por último, consideraremos algunos debates actuales que están problematizando las nociones de cine y de lo nacional, para proponer una mirada hacia el futuro.

\section{Campo de posibilidades para la consolidación de los estudios de cine en Argentina}

Los primeros años del siglo XXI encontraron al cine nacional confirmando los nuevos caminos que la camada de directores de Lucrecia Martel, Martín Rejtman, Adrián Caetano y Pablo Trapero habían abierto hacia mediados de los años ' 90 . Al mismo tiempo, hacia finales de esa década habían surgido el Buenos Aires Festival Internacional de Cine Independiente (BAFICI) y Doc Buenos Aires, dos eventos que promovieron la exhibición y circulación de novedades cinematográficas locales e internacionales. En este contexto, la crítica se había consolidado como un actor fundamental y con el crecimiento acelerado de los medios digitales, se anunciaba la proliferación de nuevos espacios para debates y discusiones. 
Partiendo de este marco, proponemos a continuación un punteo de los principales hitos que llevaron a la consolidación del campo de los estudios de cine. Para ello nos detendremos en tres ámbitos: las iniciativas editoriales de libros y revistas especializadas; el surgimiento y fortalecimiento de espacios dedicados a la investigación sobre cine y audiovisual; y la conformación de redes y asociaciones que fomentan el intercambio y la discusión académica.

\subsection{Políticas editoriales}

Las revistas de crítica y los sitios digitales significaron un primer canal para la proliferación de escritos teóricos y académicos sobre el cine. Estos espacios fueron dando lugar gradualmente a estudiosos que buscaron salir de la crítica periodística, como fue el caso de Otrocampo: Estudios de cine, sitio creado en 1999, surgido según sus editores "como respuesta a la ausencia de un espacio dedicado a la reflexión cinematográfica". Al mismo tiempo, en el terreno impreso, la revista semestral Kilómetro 111, fundada en 2001, se configuró como "la expresión paradigmática de un polo académico (nucleado aquí en las carreras de Letras y de Artes de la Facultad de Filosofía y Letras de la Universidad de Buenos Aires) de una nueva crítica, que asume su identidad precisamente en la apropiación del cine como objeto de estudio y testimonio de las nuevas alternativas de la modernidad cultural" (Amatriain, 2009: $25)^{1}$.

En 2005, en sintonía con el crecimiento de la investigación académica del cine, el Instituto Nacional de Cine y Artes Audiovisuales (INCAA) publicó una serie de Cuadernos de cine, coordinados por Clara Kriger, que proponían ejes transversales que abordaran problemas específicos del cine nacional, como la representación de los sectores sociales, la gestión estatal y la industria, las innovaciones estéticas y narrativas, el cine infantil y la enseñanza, la identidad nacional y la intertextualidad. Estas iniciativas fueron dando mayor visibilidad a un conjunto de investigadores dedicados al cine, ayudando a la difusión de sus trabajos.

Actualmente, favorecido por las posibilidades de los medios digitales, el campo de las publicaciones académicas dedicadas al cine se ha multiplicado. Por un lado se cuentan publicaciones relacionadas con otras disciplinas como la historia del arte (Caiana), la comunicación (Question), la semiótica (AdVerSus), la sociología (Lindes) o los estudios de la imagen (Sans Solei) donde el cine supone una temática recurrente. Por otro lado, revistas como Toma Uno o Imagofagia se presentan como espacios privilegiados para los debates y discusiones, con dossiers temáticos y reseñas bibliográficas. Es destacable en este sentido el caso de revistas como Cine Documental y Vivomatografías, pues suponen publicaciones sobre temas específicos, dando cuenta del crecimiento del campo ${ }^{2}$.

En simultáneo con esta expansión de revistas académicas, en el ámbito editorial se presentaron una serie de iniciativas que dieron visibilidad a trabajos con mayor densidad crítica y teórica. Por un lado se puede destacar la colección "Nuevo Cine Argentino" de la editorial Picnic que presenta análisis en profundidad de films paradigmáticos del Nuevo Cine. Asimismo, editoriales como Colihue con la colección "A oscuras - Colihue imagen", Imago Mundi y Libraria han favorecido la bibliografía sobre cine y audiovisual. Debe destacarse también las iniciativas de la Escuela Nacional de Experimentación y Realización Cinematográfica (ENERC), que en 2015 comenzó a realizar un concurso anual de estudios de cine cuyo premio es la publicación en libro de investigaciones inéditas.

\section{2 Ámbitos de investigación}


Acompañado de las mayores posibilidades de difusión y de la creciente heterogeneidad e interés de la producción fílmica, estos años vieron la multiplicación de centros académicos dedicados al estudio de la imagen audiovisual. Así como los años '90 se habían caracterizado por la profusión de escuelas de realización, la dimensión teórica e historiográfica del cine cobró especial relevancia en el nuevo siglo.

Para dar cuenta de esta multiplicidad de centros, la Comisión de Comunicación y Articulación de la Asociación Argentina de Estudios de Cine y Audiovisual se encuentra actualmente llevando adelante un relevamiento a nivel nacional en pos de ofrecer una cartografía de este campo académico. Entre las instituciones donde se desarrollan estos estudios se pueden contar diversas facultades, institutos y centros de estudios de las universidades de Buenos Aires, de Córdoba, de Villa María, de Rosario, del Litoral, de Tucumán, del Centro de la Provincia de Buenos Aires, de La Plata, de Tres de Febrero y de San Martín.

Es destacable que el significativo crecimiento de los estudios de cine se debe fundamentalmente a la política estatal de financiamiento a la investigación que generó un punto de inflexión. De este modo se multiplicaron las becas doctorales otorgadas por el Consejo Nacional de Investigaciones Científicas y Técnicas (CONICET) para los estudios sobre el audiovisual, favoreciendo el ingreso de nuevas camadas de investigadores al campo académico.

\subsection{Profesionalización del campo}

El crecimiento de la actividad académica relacionada a los estudios de cine trajo aparejado la necesidad de crear y fortalecer espacios de intercambio y discusión entre los involucrados. Así como SOCINE en Brasil o SEPANCINE en México, en 2008 se creó en Argentina la Asociación Argentina de Estudios de Cine y Audiovisual (ASAECA) con el fin de nuclear y conectar a los investigadores del campo, conformando un marco institucional para favorecer actividades de diversa índole. La primera presidenta de la asociación, Andrea Molfetta (2010), señalaba sobre el campo de estudios en aquel momento que:

Al fundar ASAECA pensamos que teníamos un área de conocimiento formada, aunque incipiente y fragmentada. Sin embargo, vimos en nuestro primer encuentro que, de hecho, tenemos un mapa de investigaciones provenientes de diversas ciencias y, como resultado, un área de estudios en formación a partir de cruces y diálogos epistémico-metodológicos en torno a los objetos de nuestra cultura audiovisual.

La asociación ha buscado profesionalizar este campo, buscando diversas vías para la producción y discusión de investigaciones locales. Dentro de las tareas llevadas adelante por ASAECA, hay tres instancias que resultan de suma relevancia:

- Los congresos internacionales realizados cada dos años desde 2009, que convocan entre trescientos y cuatrocientos estudiantes, graduados e investigadores nacionales e internacionales.

- La publicación desde 2010 de la revista Imagofagia, dedicada íntegramente a los Estudios de Cine, que se propone como un espacio donde poner de manifiesto la vasta y heterogénea producción del campo. 
- El concurso anual de ensayos Domingo Di Núbila, iniciado en 2012, organizado el marco del Festival Internacional de Cine de Mar del Plata, para fomentar los estudios sobre cine nacional.

\section{Los estudios de cine y el Nuevo Cine Argentino}

El Nuevo Cine Argentino (NCA) surgido a mediados de los años '90 significó un punto de quiebre en los distintos ámbitos del campo cinematográfico nacional. La renovación estilística, narrativa y productiva que se suscitó llevó a la necesidad de formular hipótesis y preguntas novedosas para interrogar y aprehenderlo, convirtiéndose en el primer tema dominante de los estudios de cine en Argentina en este siglo.

Las primeras reflexiones sobre el NCA se originaron en las revistas críticas contemporáneas. Fue recién en 2006, con la publicación del libro Otros mundos de Gonzalo Aguilar que se produjo un punto de inflexión, ya que en él se establecieron algunos de los principales debates dominantes de los años siguientes ${ }^{3}$. Doctor en Filosofía y Letras, Aguilar propuso una mirada que articulaba lo industrial con lo social a partir de tres ejes de análisis: el industrial, el poético/estilístico/narrativo y el político.

$\mathrm{El}$ aspecto industrial fue uno de los primeros debates suscitados en la necesidad de entender las condiciones de existencia del NCA. En este sentido, se ha profundizado en la relación de este cine con la industria fílmica nacional, tanto por la impronta parricida que le imprimió la crítica como por sus dinámicas de producción (Wolf, 2009; Daicich, 2016) ${ }^{4}$. En sintonía con estas problemáticas, y desde una perspectiva más historicista, se ha profundizado en las condiciones de surgimiento y consolidación del NCA a partir de las instituciones que lo posibilitaron. Los trabajos compilados por Ignacio Amatriain (2009) ahondan, por ejemplo, en hitos fundamentales la Ley de Cine, los apoyos de los multimedios, el Bafici, la recepción crítica y de taquilla, y los antecedentes de Martín Rejtman y los films colectivos Historias breves.

Por otro lado, la relación del NCA con la historia del cine nacional fue uno de los primero tópicos de discusión al momento de analizar su factoría. Dado su carácter heterogéneo y modernizador, el primer punto de referencia se encontró en la 'Generación del '60', un conjunto variado de directores surgidos luego de la caída del sistema industrial que buscaron renovar estilística y temáticamente el cine nacional. Fernando Peña (2003) planteó un análisis paralelo de ambos conjuntos, pensándolos desde una óptica generacional con argumentos retomados y discutidos por Nicolás Prividera (2014).

La mirada historicista fue también girando hacia la segunda mitad de la década del 2000 a la pregunta sobre la periodización del NCA y la pertinencia de este rótulo para el cine contemporáneo. Es así que el afán abarcador que englobaba obras tan diversas dentro del rótulo de Nuevo Cine Argentino comenzó a ser discutido, atomizándose para comprender el presente y repensar estas categorías ${ }^{5}$. En esta lógica, se produce una tensión entre una tendencia a la canonización del NCA y visiones críticas de su producción y sus derivaciones. Entre las primeras se destaca la compilación de Jaime Pena (2009) que nuclea a un conjunto de críticos, muchos de ellos responsables de los distintos espacios de consagración del NCA como la revista El Amante/Cine o el Bafici. Frente a ellos se posiciona Nicolás Prividera (2014) quien critica la falta de un rol activo y crítico de los cineastas del NCA y centra su análisis en la aparente despolitización de este cine.

Una segunda línea de abordaje al NCA ha sido desde un punto de vista estilístico y narrativo, con investigaciones que parten desde un análisis formal de las obras para considerar las 
rupturas y continuidades que se dan dentro de estas películas. Malena Verardi (2008), por ejemplo, decide poner el foco en la construcción de espacios y tiempos en estas películas para proponer una red de sentidos y significaciones de los films. Gonzalo Aguilar (2006), por su parte, destaca las innovaciones en el uso del sonido y las técnicas actorales.

Un tópico recurrente dentro de estos trabajos ha sido la relación del NCA con los géneros cinematográficos, como se puede observar en varios de los números de la colección Nuevo Cine Argentino de Editorial Picnic (Aguilar, 2007; Porta Fouz, 2007; Schwarzböck, 2007a; Schwarzböck, 2007b). El estudio de los géneros propone una mirada de continuidad entre el NCA y las tradiciones del cine industrial, aunque, como señala Aguilar (2006) que el uso de los géneros se da generalmente de un modo singular, tomándose sus marcos y códigos como simples puntos de partida narrativos.

Dentro de esta producción tendiente hacia formas narrativas genéricas se encuentran algunos referentes de esta generación como Pablo Trapero o Adrián Caetano. Sin embargo, otros realizadores han tendido más hacia la creación de universos personales en cuyo análisis ha primado una mirada autoral. Son estos los casos de Lucrecia Martel y Lisandro Alonso, que han sido retomados en los estudios nacionales e internacionales sobre cine argentino por sus propuestas formales y sus poéticas personales (Oubiña, 2007; Rangil, 2007; Andermann, 2012).

El tercer eje principal de los estudios sobre NCA se centra en su relación con lo real y lo político. Dentro de ello se pueden considerar los textos de Ana Amado (2009) y Eduardo Cartoccio (2016) o el libro colectivo editado por Viviana Rangil (2007), quienes abordan temáticas recurrentes de este cine como la fragmentación social, las rupturas familiares, los desencuentros generacionales y la fragilidad del mundo juvenil.

La politicidad de estos relatos e imágenes ha sido una pregunta que ha cruzado la mayoría de sus estudios. Es así que Aguilar (2006) plantea la necesidad de redefinir lo político en este campo, separándolo del espíritu de denuncia y la militancia y autonomizándolo de las intenciones pedagógicas del cine de la década anterior. Frente a ello, Prividera (2014) sostiene que este desplazamiento funcionó, en cambio, como un vaciamiento de todo contenido político y una primacía de un tono observacional despojado.

Estos debates en torno a la relación de los nuevos cineastas con la política deben ser comprendidos en un contexto más amplio, donde distintas nociones como el género, la crisis social y la memoria pasaron a un lugar más relevante dentro del campo cultural argentino. Mientras que la respuesta del cine de ficción a esta dinámica fue confusa y multidireccional, en el terreno del documental se produjo una explosión de producción y reflexión que puso estos debates en un primer plano.

\section{Documental, historia y memoria}

El siglo XXI ha visto globalmente la explosión del documental, tanto en el campo de la producción fílmica como en el de la reflexión intelectual. Destacando la riqueza de la tradición documental latinoamericana, María Luisa Ortega (2011) destaca los cambios en la circulación y la visibilidad de estas realizaciones, relacionadas con una mayor viabilidad económica y tecnológica para su producción. Factores como los que incidieron en el apogeo del NCA (festivales, escuelas de cine, reconocimiento crítico) llevaron también a una mayor atención por parte del mundo académico argentino hacia la producción documental. 
Uno de los principales puntos de interés ha sido la propia definición de lo que se entiende por documental. Desde un punto de vista historiográfico este interrogante ha requerido considerar su relación con las distintas tradiciones nacionales. Como señala Javier Campo (2012), la historia del cine documental argentino es una tarea aún pendiente, por lo cual distintos trabajos autónomos se han preguntado por la relación de momentos e hitos específicos con la tradición documental. Por ejemplo, tanto Irene Marrone y Mercedes Moyano Walker (2006) como Clara Kriger (2009), al analizar los noticiarios cinematográficos y los docudramas de propaganda, se han preguntado su lugar dentro de la historia del documental argentino.

Un lugar destacado dentro de estos abordajes históricos al documental se le ha otorgado al video, en su tensa relación con el cine y con el documental. En esta línea, un aporte de suma importancia ha sido el de Paola Margulis (2014) quien estudió la formación e institucionalización del campo documental en la posdictadura, centrándose fundamentalmente en sus condiciones materiales de producción, circulación y legitimación ${ }^{6}$. Este fenómeno ha sido retomado asimismo en los estudios sobre el videoactivismo, como es el caso de Gabriela Bustos (2006) y de Maximiliano de la Puente y Pablo Russo (2007).

Más allá de estos casos, el principal punto de referencia para la historización del documental ha sido el cine militante de los años ' 60 y ' 70 , sobre el cual nos detendremos más adelante al centrarnos en su dimensión política. Su relevancia lo ha llevado a ser un punto de referencia para pensar le documental contemporáneo. De este modo, Marrone y Moyano Walker comparan la producción de los '60 con la de la crisis del 2001 planteando que en ambos momentos se dio una crisis estructural de sentido "afectando creencias, valores, prácticas e instituciones, erosionando el discurso narrativo hegemónico de lo social. La realidad (sus modos de representación) se tornó entonces inaprensible y se volvió difícil mantener esquemas institucionales preestablecidos" (2011: 12).

El problema de lo real ha sido uno de los principales nudos del debate en el terreno del documental. Campo (2012) discute la idea del documental como pura construcción artificial, planteando que "no todo es subjetividad aplicada y punto de vista: la materialidad profunda de lo real (el referente, como dice Roland Barthes) es independiente de los hombres" (2012: $215)^{7}$. Esta misma línea reflexiva es retomada en la compilación de Gustavo Aprea y Agustín Campero (2011), donde se problematizan las tensiones entre verdad y falsedad.

La problematización de lo real se produce en sintonía con una transición a mediados de los años ' 90 hacia el predominio de la subjetividad en el documental. El surgimiento de la primera persona, la fragmentación y caída de los discursos totalizadores y la puesta en cuestión del propio estatuto del documental han sido algunas de los tópicos recurrentes en los estudios sobre documental de los últimos años. En este contexto se consolidó como eje central del campo los Estudios de la Memoria.

Ciancio (2013) señala que la memoria se encuentra ya en la tradición propia de los estudios de cine, aunque generalmente desde la hibridación del ensayo testimonial, el comentario y la periodización historiográfica. La recuperación en los años ' 90 del pasado reciente puso en un lugar destacado el acto de recordar, haciendo que pase de ser una herramienta metodológica a ser el foco de los trabajos documentales. Pasaron así a plantearse en los estudios del documental propuestas relacionadas con la posmemoria, la afectividad, la imaginación, las mediaciones y la performatividad. 
Las formas asociadas a la subjetividad, que Pablo Piedras (2014) denomina 'documentales en primera persona', han sido objetos de debates y reflexiones sobre la fragmentación de los recuerdos y la desaparición de los relatos organizadores. Piedras plantea que esta subjetividad ya se encontraba latente en el cine militante y que explota en el contexto de postcrisis de los años 2000. En este sentido, aborda el tema de la memoria desde perspectivas historiográficas, etnográficas y filosóficas, planteando que se produce un reposicionamiento del sujeto en la centralidad del discurso que origina historias orgánicas personales e incompletas.

Dos casos paradigmáticos en este sentido han sido los films $M$ y Los rubios, producciones de hijos de desaparecidos que problematizan los relatos sobre sus padres. Piedras considera que el primero se ubica en 'los bordes de la historia', renunciado a los relatos totalizadores y problematizando la reconstrucción histórica. El film de Carri responde, según el mismo autor, a una tendencia a la memoria laberíntica donde el recuerdo se vuelve imposible al llenarse de rodeos y mediaciones. En una línea similar, Mauricio Alonso (2007) señala que Carri le da la espalda a la Verdad como finalidad argumentativa, dejando de lado el pasado para tratar el presente y su relación con el dolor.

Dentro de este debate ha sido de suma importancia los aportes de Gustavo Aprea (2015), quien sostiene la necesidad de pensar al cine como fuente y agente de la memoria. Destaca de este modo el rol activo del documental en la manipulación de los discursos históricos a través de mecanismos de manipulación como el olvido y la superposición de recuerdos. Al mismo tiempo, resalta nuevamente la dimensión subjetiva que prima en el recuerdo al destacar que "en estos documentales es tan importante lo que se recuerda como la exhibición del acto de recordar" (2015: 14).

Los trabajos de Aprea dirigen su mirada hacia el lugar de los testimonios, al poner en primer plano la pregunta sobre qué, cómo, quiénes y desde dónde recuerdan. Desde esta óptica, el testimonio deja de ser solamente un ampliador de información, para tomar un rol central en la formación de una memoria colectiva que tensiona y problematiza los recuerdos individuales. Aquí los planteos en torno a la ética toman una especial relevancia, como señala Lorena Moriconi (2012) al indagar sobre las mecánicas de poder y la dimensión de lo intestimoniable en su aplicación al documental latinoamericano.

Frente a estas reflexiones en torno a cómo se construye la memoria dentro del documental, la propuesta de Lior Zylberman (2012) es centrarse en el contrato que realiza el espectador con el audiovisual. De este modo, agrega una nueva dimensión a esta problemática, proponiendo pensar a la memoria como una relación de imaginación. Asumiendo una perspectiva pragmático-fenomenológica retoma la idea de la 'experiencia', destaca la fragilidad de las imágenes y la necesidad de problematizar la relación del espectador con el pasado ${ }^{7}$.

Aprea (2015) señala que la irrupción de estas preocupaciones se debe a la articulación del documental con la serie social y política. La recuperación del pasado traumático ha apelado en gran medida a los relatos audiovisuales, ya que "poseen cualidades que los convierten en vehículos idóneos para la creación de recuerdos que sostienen memorias colectivas nacionales, de clase, étnicas, de género- y la transmisión y conservación de interpretaciones del pasado que soportan las identidades sociales." (2015: 14). Es así que gran parte de los estudios sobre la memoria se encuentran ligados a los derechos humanos, como el libro de Javier Campo y Christian Dodaro (2007), impulsado por el Movimiento de Documentalistas. Es así que la politicidad que se le reclamaba al NCA toma un lugar central en los estudios del 
documental, excediendo al audiovisual y ahondando en las construcciones de sentido del pasado en la sociedad ${ }^{8}$.

\section{Cine y política}

La dimensión política del cine ha cruzado y configurado tanto los estudios sobre el NCA como sobre el documental. Así como la propuesta de Gonzalo Aguilar marcó un punto de inflexión en los abordajes del nuevo cine, el pensamiento sobre lo político tuvo en el libro La mirada justa (2009) de Ana Amado una formulación y sistematización que estableció algunos de sus ejes fundamentales como las problemáticas generacionales, las relaciones de lo político con lo estético y lo formal y las nuevas formas identitarias.

$\mathrm{Al}$ igual que con el documental, podemos detectar aquí una perspectiva historiográfica que busca trazar las tradiciones del cine político y otra que lo aborda desde visiones teóricas o estéticas, problematizando la dimensión política del cine contemporáneo. En la primera tendencia se destacan los dos tomos de la historia del cine político y social realizados por el Centro de Investigación y Nuevos Estudios sobre Cine (CIyNE), dirigido por Ana Laura Lusnich (2009, 2011), que proponen una tradición histórica desde el cine silente a la actualidad. Retomando los postulados del trabajo de Octavio Getino y Susana Velleggia (2002), abordan un conjunto de producciones, tanto del cine industrial como de ámbitos independientes, para proponer una mayor complejidad al universo del cine político.

Esta propuesta historiográfica no ha sido, sin embargo, tan profundizada o discutida como lo fueron los cines militantes de los años '70, fundamentalmente las experiencias de la Cine Liberación y Cine de la Base. Inicialmente, como se percibe en el $\mathrm{N}^{\circ} 2$ de Kilómetro 111 o en las publicaciones de Fernando Martín Peña (2000; 2003), se retomó a este cine desde una lógica de recuperación de un pasado muchas veces desconocido y necesario de reivindicación. Como señalara Gustavo Aprea (2015), esta vuelta al pasado traumático llevó a un lugar destacado dentro de los estudios de cine.

Un referente fundamental en este aspecto fue Mariano Mestman, quien ahondó tanto en los aspectos representacionales como en las condiciones de existencia del cine militante. En diversos artículos y capítulos de libros ha abordado el campo cultural en que se desarrollaron estas prácticas. Por otro lado, publicó en los Cuadernos de la Red de Historia de los Medios (ReHiMe) (2014) una serie de documentos ligados al Encuentro de Montreal de 1974 donde confluyeron los principales referentes del cine político latinoamericano. A partir de ello, destacando su valor arqueológico, profundizó en los debates del período, la tensión nacionaltrasnacional, la intervención social, los posicionamientos políticos y las discusiones con los exhibidores europeos.

El trabajo de Mestman se inserta en las líneas de investigación que han profundizado sobre la dimensión internacional del cine militante, desde la comparación de Cine Liberación y Cinema Novo de Tzvi Tal (2005) a las propuestas regionales de Silvana Flores (2013) ${ }^{9}$. Frente a estas líneas dominantes, Mestman ha planteado recientemente en el libro, Las rupturas del 68 (2016), la necesidad de revisar el carácter canónico que ha tomado el cine militante en los textos académicos, matizándolo y poniéndolo en relación con otras formas innovadoras del período.

La revisión del cine militante no se ha limitado a pensarlo desde una perspectiva histórica, sino que muchas veces ha sido retomado como referencia para el presente. Esta postura se presenta en el libro editado por Marrone y Moyano Walker (2011) que relaciona el boom 
documental con los estallidos sociales y las necesidades de dar sentido a los momentos de crisis. De igual modo, Rangil (2007) se pregunta por la validez los postulados del Nuevo Cine Latinoamericano para considerar el Nuevo Cine Argentino, tomando como ejes tanto documentales como ficción.

Estos trabajos suelen retomar la idea de documental político, concepto problematizado en su polivalencia por el libro de Sartora y Rival (2007). Allí ahondan en las características del cine militante contemporáneo y las distintas formas del activismo audiovisual. Un rol central aquí toma el videoactivismo y el cine piquetero que presentan una nueva serie de problemáticas de orden teórico.

Al poner en tensión el propio dispositivo fílmico y sus instancias de producción y exhibición, las nuevas formas del cine militante reclamaron otro tipo de abordajes. Gabriela Bustos (2006) propone pensar a estos colectivos desde la idea de un cine de intervención, proponiendo una mirada interdisciplinaria que incluye una topografía de su producción, una sociología de su formación, un análisis fílmico, y una construcción teórica a partir de sus objetivos políticos. Esta misma idea de intervención es retomada por Maximiliano de la Puente y Pablo Russo (2007), quienes consideran central el objetivo del cine piquetero de contrainformación, búsqueda de cambio social y toma de conciencia. A partir de un relevamiento de las principales iniciativas, refuerzan la necesidad de abordarlos desde una perspectiva que integre la estética con la política y que tenga en cuenta el carácter de urgencia que caracteriza a esta producción.

Los cambios de formatos y contexto se presentan también en la propuesta de Ana Amado (2009) de repensar las formas estéticas y narrativas de lo político en un contexto de despolitización. Señala así la necesidad de cambiar la mirada al plantear que no se debe buscar solamente a un vínculo directo y militante, sino que lo político se manifiesta también en alusiones a la realidad. Dada la transformación de los criterios estéticos y el surgimiento de nuevas formas visuales y narrativas, señala que no pueden ser comprendidas desde las categorías tradicionales. Tomando nuevamente el caso de Los rubios, Amado señala que el film propone un gesto estético-político a partir de la inestabilidad de sus formas que interpela la estabilidad de la política, diluyendo el drama y la victimización, estableciendo nuevos modos de politización de la imagen.

Dentro de los nuevos modos de representación a los que alude Amado, los estudios sobre la relación del cine con la política también han retomado el lugar de la subjetividad y la emergencia de la primera persona (individual o colectiva). Como señala Aprea (2008), al pensar la relación del cine con las políticas, el nuevo cine social y político se caracteriza por dar lugar a discursos sobre la mujer y sobre las relaciones familiares y sociales. De este modo apunta ya no a grandes discursos de transformación sino a atender a los sectores subalternos y los distintos colectivos de lucha.

Es en este sentido que podemos pensar la emergencia de los estudios de género en torno al audiovisual como correlato de estas transformaciones de las prácticas productivas y representacionales. Ciancio (2013) destaca la importancia de los postulados de Judith Butler en transformar las perspectivas de género a partir de la noción de performatividad, destacando textos como los de Constanza Burucúa (2009) o las relaciones del género con la memoria presentes en los escritos de Ana Amado ${ }^{10}$.

Las preocupaciones de esta perspectiva no se limitan solamente a análisis de discursos y representaciones sino también al quehacer fílmico. Es así que tanto Viviana Rangil (2005) 
como Agustina Pérez Rial y Paulina Bettendorf (2014) se centran en el recambio producido dentro del campo de la producción con la irrupción de un gran número de mujeres en espacios anteriormente dominados por los hombres. Pérez Rial y Bettendorf proponen no pensar en 'cine femenino', sino en "explorar los discursos, las experiencias y los modos de percepción de y sobre el cine de mujeres"

En una misma línea han comenzado a tomar mayor espacio los estudios queer y de diversidad sexual. Adrián Melo (2008), por ejemplo, compiló un conjunto de artículos que no sólo atienden la producción contemporánea sino que proponen nuevas visiones sobre líneas subterráneas que han cruzado la historia del cine nacional. De este modo, estas nuevas formas de politicidad del cine comienzan a cruzarse con la historiografía y la revisión de las tradiciones vernáculas ${ }^{11}$.

\section{Transitando la historia del cine}

Las líneas hasta aquí planteadas de los estudios de cine en Argentina se pueden enmarcar dentro de esta irrupción del campo en el nuevo siglo. En estas áreas ha primado una conformación a partir de disciplinas académicas y de líneas de investigación ya presentes en los estudios literarios, la filosofía o la psicología. Proponemos a continuación detenernos en el modo en que la consolidación de este campo dentro de la investigación científica implicó una profunda transformación en uno de los espacios más transitados en la bibliografía sobre cine: su historia.

La tradición historiográfica en Argentina fue en un primer momento potestad de críticos periodísticos que planteaban miradas totalizadoras. Pedro Sorrentino (2011) diferencia a los 'historiadores académicos' de los 'historiadores críticos', donde profundiza en el contexto institucional y los marcos metodológicos utilizados para plantear el surgimiento de nuevas camadas. El año 2000 significó un momento de transición entre ambos grupos, como se evidencia en la publicación de los dos tomos de Cine argentino: Industria y clasicismo, dirigidos por Claudio España. En esta colección se puede percibir la transición generacional, ya que allí conviven trabajos de investigadores provenientes de la tradición crítica y periodística con las primeras camadas de graduados de la Facultad de Filosofía y Letras de la Universidad de Buenos Aires dedicados a los estudios de cine.

Un aspecto fundamental para destacar antes de adentrarnos en los ejes fundamentales de la investigación historiográfica es el problema que ha existido históricamente en el país con respecto a la política de archivos y patrimonio. Martín Miguel Pereira (2015) estudió estas cuestiones, señalando los recorridos legales de la Cineteca Nacional, legislada en 1998 pero aún inexistente, y las distintas iniciativas parciales de conservación. Para la profusión de estudios históricos ha resultado fundamental, por lo tanto, la revolución digital que ha brindado acceso a fuentes históricas, periodísticas y fílmicas desde distintos puntos del planeta y a contactos nacionales e internacionales entre coleccionistas aficionados, críticos e investigadores $^{12}$. Es destacable asimismo la tarea del Museo del Cine o de Aprocinain (Asociación de Apoyo al Patrimonio Audiovisual), con restauraciones como Mosaico Criollo, antología de cine silente editada en 2009 , y de diversas producciones de la historia del cine nacional.

Proponemos a continuación señalar los principales referentes de los trabajos sobre la historia del cine nacional a partir de la periodización tradicional:

\subsection{El cine silente}


El historiador Domingo di Núbila señalaba a este período como una prehistoria al verdadero cine argentino. Frente a esta mirada han surgido una cantidad de trabajos dedicados a este cine en los que, como señala Andrea Cuarterolo (2013b), se rechaza la mirada teleológica y se persigue la necesidad de dotar de mayor autonomía a los estudios sobre el período. En este sentido ha resultado de suma importancia el trabajo en conjunto con investigadores de otros países para la realización de seminarios específicos y la publicación de una revista semestral, Vivomatografias, Revista de estudios sobre precine y cine silente en Latinoamérica.

Una característica que une a todos estos trabajos es la de una labor minuciosa de archivo y búsqueda de fuente para la reconstrucción de una filmografía mayormente perdida, llevando muchas veces a hallazgos y recuperaciones de material fílmico. Entre ellos se pueden destacar los de Irene Marrone (2003) quien aborda los noticiarios y los documentales institucionales, deteniéndose en figuras destacadas como Max Glücksmann y Federico Valle, articulando la construcción del discurso documental con el mundo de las representaciones y las prácticas de sentido de las imágenes. Deteniéndose también en el documental, Andrés Levinson (2011) se adentra en las realizaciones filmadas en esos años en la Patagonia. Por su parte, Andrea Cuarterolo (2013a) propone un abordaje del cine silente en una línea de continuidad con la fotografía, tomando en cuenta desde sus circuitos de exhibición a las transformaciones que estas formas visuales generaron en las formas de percepción ${ }^{13}$.

\subsection{El cine clásico}

Dentro de la historiografía del cine nacional, el período clásico ha sido quizás el más visitado, pero al mismo tiempo su tratamiento ha sido muchas veces superficial. Es aquí donde se hacen más presentes nociones provenientes de la crítica como la idea de una 'Edad de oro' del cine argentino y la existencia de un canon de películas, directores y temas. La investigación académica ha buscado generalmente discutir algunos de estos preceptos a partir de trabajos de fuentes y nuevos marcos teóricos.

Se pueden destacar en esta línea aquellos estudios que se han centrado en aspectos asociados con los sistemas propios del modelo industrial, fundamentalmente los géneros y las estrellas, buscando ahondar en su conformación interna y los contratos establecidos con el público y la serie social. Aquí podemos señalar las investigaciones doctorales en curso de Soledad Pardo y Florencia Calzón Flores sobre el sistema de estrellas, el trabajo doctoral de Alejandro Kelly Hopfenblatt sobre la comedia sofisticada y el libro de Ana Laura Lusnich (2007) sobre el drama social-folclórico ${ }^{14}$.

Por otro lado, más cercanos a una historia política o industrial del cine. Se encuentran aproximaciones como las de Raúl Horacio Campodónico (2005) y Clara Kriger (2009). El primero propone una perspectiva económica del período clásico para buscar dar cuenta de las circunstancias que condicionaron el desarrollo industrial. El trabajo de Kriger, por su parte, se posiciona frente a la visión denigratoria que dominó la historiografía sobre el cine durante el peronismo, para adentrarse en un minucioso análisis de las políticas cinematográficas del período.

Profundizando en algunos de estos planteos, se deben destacar en los últimos años la aparición de trabajos que comienzan a abordar el cine clásico desde una perspectiva transmedial como parte de una estrategia de convergencia de medios junto con la radio, la industria discográfica o el teatro. Libros como los de Matthew Karush (2013) o Cecilia Gil Mariño (2015) han profundizado en estos aspectos, introduciendo nociones de los estudios 
culturales y perspectivas ligadas a los estudios de recepción y los problemas de la modernidad periférica.

\subsection{El cine moderno}

Los años sesenta, con la caída del sistema industrial y la irrupción de los cines modernos, cuentan con menor bibliografía que los otros períodos aunque han sido objeto de diversas tesis doctorales recientes. Si bien, como se ha señalado, este período suele ser pensado más en relación con los cines militantes, el devenir de la 'Generación del 60' y el denominado 'Grupo de los5', los dos mayores exponentes de las nuevas camadas de directores, han dado lugar a algunos estudios que los abordan como parte de la modernidad cultural vernácula.

Un punto disparador de ello se puede encontrar en Generaciones 60/90 (2003), el libro de Fernando Martín Peña que retoma a aquel primer Nuevo Cine Argentino planeando problemáticas como la idea de fracaso generacional, las búsquedas de identidades propias asociadas al mundo juvenil y las relaciones con las políticas estatales. Posteriormente han comenzado a realizarse trabajos más pormenorizados que generalmente han abordado estas producciones desde el concepto de campo cultural, leyéndolo en el marco de fenómenos producidos en el campo artístico e intelectual de la época. En este marco podemos señalar los de Ana Broitman (2014), los trabajos doctorales de Jorge Sala y Paula Wolkowicz y el libro de Marcela Raggio (2011) sobre Leonardo Favio, que dan cuenta de un terreno polifónico que aún necesita ser estudiado.

Es necesario destacar que estas investigaciones suelen circunscribirse a la 'larga década del '60’ (1959-1973), por lo cual todavía no ha habido mayor bibliografía que considere la producción no militante posterior. Es recién en los últimos años que han comenzado a plantearse investigaciones que aborden el cine industrial de los '60 a los ' 80 , permitiendo miradas que se abran de la perspectiva eminentemente política y consideren las cuestiones industriales, estéticas y tecnológicas que se dieron en esos años.

\subsection{Otros ámbitos de la historia del cine}

Por fuera de la producción cinematográfica ha habido otros temas que han sido abordados desde la historiografía con sus propias periodizaciones. Entre ellos se pueden destacar, por ejemplo, el Festival de Cine de Mar del Plata (Neveleff, Monforte y Ponce de León, 2013; 2014) o las salas de exhibición (Méndez y García Falcó, 2010). Dentro de estos campos por fuera de la producción de cine, hay dos objetos en particular que han recibido mayor atención. Tanto la crítica como la censura pueden pensarse en relación con las miradas económicas o políticas, pero al mismo tiempo su carácter periférico ha permitido el planteo de preguntas propias y periodizaciones individuales.

Sobre la crítica se destaca en primer lugar la colección de Páginas de cine (2003) y el dossier publicado en el $\mathrm{N}^{\circ} 5$ de Imagofagia, dirigidos ambos por Clara Kriger que proponen una mirada general de la historia de la crítica, señalando problemas generales e hitos fundamentales que la han caracterizado. En relación con ello, la colección Los escritores van al cine editada por Libraria y dirigida por Gonzalo Aguilar, busca cruzar la historia intelectual con la experiencia cinematográfica al recoger los textos sobre cine de destacados escritores como Jorge Luis Borges o Victoria Ocampo. Recientemente el libro La mirada cinéfila de Daniela Kozak (2013), centrado en la renovación modernista de la crítica a partir de la revista Tiempo de Cine, abrió una nueva línea de historia de la crítica que no ha sido profundizada todavía ${ }^{15}$. 
La censura, por su parte, fue históricamente un ámbito aludido por las historias del cine, pero no abordado de manera sistemática y profunda. Los trabajos de Hernán Invernizzi (2006; 2014) y Fernando Ramírez Llorens (2015) han buscado dar cuenta de su existencia e influencia a lo largo de la historia del cine nacional, considerando tanto sus dimensiones estatales como el rol jugado por diversos actores sectoriales. De este modo se ha profundizado en una desarticulación de idearios instalados que asociaban la práctica censora solamente con los períodos dictatoriales, mostrando su pervivencia y mutaciones a lo largo de la historia ${ }^{16}$.

\section{Reflexiones teóricas sobre el cine}

Los estudios de cine de América Latina han tendido generalmente a centrarse en aquellos aspectos específicos de la región. En Argentina esto ha llevado a la primacía de investigaciones sobre el cine nacional, ya sea su historia, su contemporaneidad, su relación con la política o la explosión del documental. El campo de la teoría no es tan asiduo, aunque temas como la memoria han llevado a este tipo de formulaciones. En este sentido, dentro de los estudios de cine en el siglo XXI se puede identificar un conjunto de autores que han profundizado en discusiones teóricas internacionales.

Ciancio (2013) señala en este marco la aparición, en medio del proceso de autonomización de los estudios de cine en el país, de diversas compilaciones de textos que tratan sobre los vínculos entre cine y filosofía, como las realizadas por el Festival de Cine de Mar del Plata (2007), la de Diego Parente (2005) y la de Gerardo Yoel (2004). Esta última destaca sus ansias de articulación con el campo nacional al presentarse como "una publicación significativa que difunde la obra de pensadores de una dilatada trayectoria internacional y la relaciona con la producción de autores locales que trabajan dentro del mismo tipo de reflexión" (2004: 11).

En este campo nuevamente se puede percibir el cruce con la crítica en revistas como Kilómetro 111, y trabajos como el de Domin Choi (2009), quien retoma las tensiones y los estados de la crítica, repensando el lugar de los postulados de André Bazin en la contemporaneidad. El lugar vertebral de la mirada cahierista en la reflexión teórica argentina sobre cine también ha llevado a revisiones a algunos de sus postulados. Eduardo Russo (2008), por ejemplo, retoma la noción de cine clásico para desarmarlo y comprenderlo como una construcción teórica y discursiva. A partir de una revisión bibliográfica sobre el concepto, interroga sus formas, estilos y funciones, tanto en su historicidad como en su contemporaneidad.

Por otro lado, otros autores se han interrogado sobre aspectos relacionados a la semiótica como Mabel Tassara (2001), que aborda problemas de la narrativa cinematográfica y discute los límites de su poética. Mario Carlón $(2006 ; 2016)$ indaga en estas líneas cruzándolas con los postulados de Christian Metz, sintetizando preocupaciones sobre la comunicación y el lenguaje. Sergio Wolf (2004) por su parte, propone una sistematización de las relaciones entre literatura y cine a partir de la noción de transposición.

Desde el campo de la filosofía también se ha considerado al cine, como en el caso de Edgardo Gutiérrez (2010), quien a partir de la discusión sobre el cine y lo real, profundiza en debates sobre el lugar de la percepción. Un caso destacado en este campo es el de David Oubiña. Doctor en Letras, crítico y guionista aborda el cine desde visiones filosóficas que lo llevan a preguntarse por su ontología, su técnica o, en el caso de El silencio y sus bordes (2011), el concepto de 'lo extremo'. Allí propone tomar un conjunto de obras fílmicas y literarias para pensar en los límites de lo moderno y la potencia perturbadora de lo extremo. 


\section{Entre lo regional y lo trasnacional}

El campo de los estudios de cine supone un terreno fluctuante en sus intereses y líneas de investigación. Así como el Nuevo Cine Argentino y el documental han tomado un lugar dominante en los últimos años en Argentina, hay otras vertientes que comienzan a emerger con fuerza últimamente, renovando intereses. Entre ellas podemos destacar una tendencia reciente a discutir las ideas en torno a 'lo nacional' desde una doble perspectiva: lo trasnacional y lo regional.

Los estudios trasnacionales tomaron en la última década un marcado impulso en el mundo académico internacional, favorecido en gran parte por nuevas vías de intercambio y circulación de saberes y personas. En Argentina, la trasnacionalidad ha brindado nuevas realidades al campo de la producción, fenómeno estudiado por Marina Moguillansky (2016) con respecto al impacto sobre la realización de las políticas del Mercosur. Preguntándose por los grados de integración regional que se puedan haber dado a partir de estos cambios económicos, señala que la presencia de corporaciones transnacionales que escapan a las políticas nacionales ha limitado el impacto del Mercosur sobre las industrias fílmicas ${ }^{17}$.

Esta idea de integración regional ha estado presente también en otras propuestas, como la del libro compilado por Eduardo Russo (2008), donde David Oubiña traza un lineamiento histórico de los proyectos regionales desde los años '60 hasta la actualidad. En esta misma dirección podemos retomar los trabajos citados anteriormente de Tzvi Tal (2005), Silvana Flores (2013) o Mariano Mestman (2016) con respecto a los nuevos cines latinoamericanos, producción donde los idearios trasnacionales fueron parte de la propia lógica de realización.

Sin embargo, en los últimos años se han realizado una serie de investigaciones que han permitido pensar desde una perspectiva trasnacional la historia del cine argentino. Metodológicamente se ha privilegiado el campo de relaciones de pares, pensando en los diálogos y conexiones establecidos por la industria argentina con algunos de sus principales socios y competidores. Cecilia Gil Mariño en su investigación doctoral ha estudiado los vínculos con Brasil durante el período clásico, mientras que ha habido proyectos colectivos como el desarrollado entre Argentina y España (2011) para ahondar en los lazos entre ambos países. En la misma línea, el grupo CIyNE, dirigido por Ana Laura Lusnich (2016), ha llevado adelante una investigación colectiva de pronta publicación sobre las relaciones entre Argentina y México durante el período clásico ${ }^{18}$.

Así como la perspectiva trasnacional tensiona la noción de lo nacional al ponerlo en relación con otras tradiciones, la mirada regional propone la coexistencia hacia el interior de lo nacional de distintas identidades. En este sentido, uno de los mayores desafíos actuales es la federalización de los estudios de cine y la consolidación de distintas voces a su interior. Frente a la primacía histórica de Buenos Aires, tanto Córdoba como Rosario se han consolidado como centros de profunda y diversa actividad en este campo académico ${ }^{19}$.

En esta perspectiva, uno de los ejes fundamentales que han tomado los estudios de cine de los diversos puntos del país ha sido la historización regional, destacando las particularidades de cada lugar. Se presentan así casos como el de Silvia Romano (2002) quien destaca el rol de la televisión en la canalización de inquietudes asociadas al cine en Córdoba, o Ignacio Dobree (2014) que piensa el cine independiente desde su lugar de trabajo en la Patagonia, destacando el rol del Super 8 y de instituciones locales como el Archivo Regional de Cine Amateur (ARCA). 
La perspectiva regional ha tensionado, por lo tanto, los discursos en torno a lo nacional, proponiendo una atomización y disgregación del concepto. Como el giro subjetivo planteado anteriormente, esta tendencia supone discutir discursos totalizantes tradicionales para proponer una sumatoria de experiencias particulares. Al igual que la trasnacionalidad, esta mirada es un emergente lógico de la consolidación del campo de los estudios de cine en Argentina al orientar su discusión a uno de los conceptos fundacionales de su objeto de estudio.

\section{El cine en la era del audiovisual}

Junto con el debate sobre lo nacional se ha consolidado en los últimos años otra discusión más amplia, de carácter internacional contemporáneo, que atiende a una de las preguntas iniciales de todos los estudios de cine: ¿qué es el cine? Aquí entra en juego una dimensión poco mencionada a lo largo de este artículo que es el rol de la tecnología y, fundamentalmente, la puesta en cuestión del estatuto del cine frente al advenimiento de lo digital. En este campo han confluido nuevamente desde filósofos a especialistas en comunicación, intentando sistematizar y aprehender un objeto de estudio en constante y frenética transformación.

Esta cuestión fue planteada en los números 4 y 5 de Kilómetro 111, donde la pregunta sobre el cine contemporáneo abordaba distintos matices, planteando ejes como la virtualidad, la modernidad y la idea de la 'muerte del cine'. Partiendo también desde una mirada filosófica, David Oubiña (2009) toma la pregunta sobre la tecnología desde una perspectiva que presenta la historia de la representación cinematográfica como un juego de visiones y reflexiones. Retomando las experimentaciones del pre-cine, Oubiña toma estos 'juguetes' para proponer una línea histórica desde donde pensar el video y el digital.

Más allá del rol fundamental de la tecnología digital, es importante destacar en esta línea de trabajo aquellos estudios dedicados a las tradiciones del cine experimental y el video arte como antecesoras de la pregunta sobre el estatuto del cine. Rodrigo Alonso y Graciela Taquini (1999), Andrea Molfetta (2013) y la investigación doctoral de Paula Wolkowicz han analizado las tradiciones del videoarte en Argentina, recogiendo las experiencias provenientes del underground y la experimentación artística de los años '60.

Sobre fenómenos más recientes se destaca la investigación de Clara Garavelli (2014) quien retoma el video experimental argentino contemporáneo, separándolo de la idea de videoarte. De este modo el foco de Garavelli se detiene sobre el lugar de la imagen electrónica y el rol del video como espacio de nuevas manifestaciones estéticas, lugar de reflexividad y performatividad, aspecto trabajado también por Gabriela Bustos (2006) y Maximiliano de la Puente y Pablo Russo (2007) en su relación con la práctica política. La propuesta de Garavelli es trascender esas prácticas puntuales para ahondar en las transformaciones que implica la aparición de lo digital, incorporando dentro de su estudio museos, video instalaciones, producciones de todo el país y estableciendo vínculos entre la práctica experimental y la serie política y social ${ }^{20}$.

Es en esta dirección donde el surgimiento de lo digital está requiriendo nuevas perspectivas teóricas y metodológicas para los estudios de cine. Entre estas búsquedas se pueden destacar desde las propuestas semióticas de Mario Carlón (2006; 2016) para pensar el post-cine y la post-tv a la compilación Recorridos (Sel, Pérez Fernández y Armand, 2011) donde se problematizan el arte, la tecnología, el mercado y la educación en la era digital. Una de las 
principales indagaciones en esta línea de trabajo ha sido la de Jorge La Ferla. En su libro El cine digital (2009) se pregunta qué es el cine después de la irrupción del digital y plantea la necesidad de comenzar a discutir la transformación tecnológica. Para ello retoma la idea de hibridez como herramienta para considerar los cruces entre lo tecnológico y lo discursivo y rechaza las posturas extremas que proclaman la muerte del cine.

Para abordar este nuevo terreno desconocido, La Ferla reconoce que lo digital excede el campo de los estudios de cine y requiere de otras disciplinas como los estudios culturales, las artes y las ciencias duras. Aquí se puede volver a considerar la propuesta inicial de este artículo que considera a los estudios de cine como un ámbito de confluencia de distintas tradiciones y disciplinas. Siguiendo la propuesta de La Ferla de tomar el 'cine expandido', ampliando el campo a las experiencias de las tecnologías electrónicas y digitales, se abre un nuevo camino para los estudios de cine que implicará rever la propia definición de su objeto de estudio.

\section{Bibliografía}

10.1 Bibliografía sobre Nuevo Cine Argentino

Aguilar, G. (2006). Otros mundos. Un ensayo sobre el nuevo cine argentino. Buenos Aires: Santiago Arcos Editor.

-- (2007). Estudio crítico sobre El bonaerense. Buenos Aires: Picnic Editorial.

Andermann, J. (2012). New Argentine Cinema. London: I.B. Tauris.

Bernini, E. (2007). Estudio critico sobre Silvia Prieto. Buenos Aires: Picnic Editorial.

Campero, A. (2009). Nuevo Cine Argentino. De Rapado a Historias extraordinarias. Buenos Aires: Universidad Nacional de General Sarmiento - Biblioteca Nacional.

Cartoccio, E. (2016). Modos de salir del hogarpaterno. Representaciones familiares y derivas juveniles en el Nuevo Cine Argentino, 1996-2005. Buenos Aires: Libraria.

Croci, P. (2007). Estudio crítico sobre El abrazo partido. Buenos Aires: Picnic Editorial.

Daicich, O. (2016). El nuevo cine argentino (1995-2010). Vinculación con la industria cultural cinematográfica local e internacional y la sociocultura contemporánea. Villa María: Eduvim.

Druetta, S. et al (2005). A la luz del trabajo: las representaciones de lo laboral en el cine argentino de los '90. Córdoba: Cominic-arte Editorial.

Noriega G. (2007). Estudio crítico sobre Los rubios. Buenos Aires: Picnic Editorial.

Oubiña, D. (2005). Martín Rejtman: el cine menguante. Buenos Aires: Fundación Eduardo F. Constantini - MALBA.

-- (2007). Estudio crítico sobre La ciénaga. Buenos Aires: Picnic Editorial.

Porta Fouz, J. (2007). Estudio crítico sobre El aura. Buenos Aires: Picnic Editorial. 
Peña, F.M. (2003). Generaciones 60-90: Cine argentino independiente. Valencia: Ediciones de la Filmoteca (Instituto Valenciano de Cinematografía Ricardo Muños Suay).

Prividera, N. (2014). Elpaís del cine. Para una historia política del Nuevo Cine Argentino. Córdoba: Los Ríos.

Rodríguez, C. (2014). El cine de terror en Argentina: producción, distribución exbibición y mercado (2000-2010). Bernal: Universidad de Quilmes.

Sassi, H. (2007). Estudio crítico sobre Hoteles. Buenos Aires: Picnic Editorial.

Schwarzböck, S. (2007a). Estudio crítico sobre Crónica de una fuga. Buenos Aires: Picnic Editorial.

-- (2007b). Estudio crítico sobre Un oso rojo. Buenos Aires: Picnic Editorial.

Verardi, M. (2008). Nuevo Cine Argentino. Formas de una época. Berlín: Editorial Académica Española.

VV AA (2002). El nuevo cine argentino. Temas, autores y estilos de una renovación. (Eds. H. Bernades, D. Lerer y S: Wolf). Buenos Aires: Ediciones Tatanka.

VV AA (2007). Cines al margen. Nuevos modos de representación en el cine argentino contemporáneo. (Eds. M.J. Moore y P. Wolkowicz). Buenos Aires: Libraria.

VV AA (2007). El cine argentino de hoy: entre el arte y la politica. (Ed. V. Rangil). Buenos Aires: Biblos.

VV AA (2008). Poéticas en el cine argentino: 1995- 2005. (Ed. M. Paulinelli). Córdoba: Comunicarte Editorial.

VV AA (2009). Una década de Nuevo Cine Argentino (1995-2005). Industria, crítica, formación, estéticas. (Coord. I. Amatriain). Buenos Aires: Fundación Centro de Integración, Comunicación, Cultura y Sociedad, CICCUS

VV AA (2009). Historias extraordinarias. Nuevo Cine Argentino, 1999-2008. (Ed. J. Pena). Madrid: T\&B Editores.

VV AA (2009). Cine argentino. Estéticas de la producción. (Comp. S. Wolf). Buenos Aires: BAFICI [11].

VV AA (2010). ¿Ficción o realidad nacional? La puesta en escena cinematográfica a fines del siglo XX como problemática de identidad. (Coord. M.J. Tristán). Villa María: Eduvim.

10.2 Bibliografía sobre Documental, Memoria e Historia

Alonso, M. (2007). Los rubios: otra forma, otra mirada. En J. Sartora y S. Rival (Eds.), Imágenes de lo real: La representación de lo político en el documental argentino (pp. 157-170). Buenos Aires: Libraria.

Aprea, G. (2015). Documental, testimonios y memorias: miradas sobre el pasado militante. Buenos Aires: Manantial. 
Campo, J. (2012). Cine documental argentino: entre el arte, la cultura y la politica. Buenos Aires: Ediciones Imago Mundi.

Feller, E. (2013). Detrás del árbol. Investigación para el documental: entrevistas con documentalistas argentinos. Buenos Aires: Eudeba.

Garavelli, C. (2014). Memorias en transición. Producciones videográficas argentinas contemporáneas entre el video de creación y el corto documental. Cine Documental 9, Buenos Aires. Recuperado de http://revista.cinedocumental.com.ar/memorias-en-transicionproducciones-videograficas-argentinas-contemporaneas-entre-el-video-de-creacion-y-elcorto-documental/

López, M. y Rodríguez, A. (2009). Un país de película: La bistoria argentina que el cine nos contó. Buenos Aires: Del Nuevo Extremo.

Margulis, P. (2014). De la formación a la institución: el documental audiovisual argentino en la transición democrática (1982-1990). Buenos Aires: Ediciones Imago Mundi.

Moriconi, L. (2012). Voces filmadas: cine documental, testimonio y dictadura (Argentina, 1983-2002). Cine Documental 6, Buenos Aires. Recuperado de http://revista.cinedocumental.com.ar/6/teoria.html

Ortega, M. L. (2011). Una (nueva) cartografía del documental latinoamericano. Cine Documental 4, Buenos Aires. Recuperado de http://revista.cinedocumental.com.ar/4/articulos 04.html

Piedras, P. (2014). El cine documental en primera persona. Buenos Aires: Paidós.

Rodríguez, A. (2015). Historia, pueblos originarios y frontera en el cine argentino. Bernal: Universidad Nacional de Quilmes.

Zylberman, L. (2012). La imaginación como prótesis de memoria. Observaciones en torno al cine documental latinoamericano. Cine Documental 5, Buenos Aires. Recuperado de http://revista.cinedocumental.com.ar/5/articulos 01.html

VV AA (2006). Persiguiendo imágenes. El noticiario argentino, la memoria y la historia (1930-1960). (Eds. I. Marrone y M. Moyano Walker). Buenos Aires: Ediciones del Puerto.

VV AA (2007). Imágenes de lo real: La representación de lo político en el documental argentino. (Eds. J. Sartora y S. Rival). Buenos Aires: Libraria.

VV AA (2007). Cine documental, memoria y derechos humanos. (Eds. J. Campo y C. Dodaro). Buenos Aires: Nuestra América.

VV AA (2010). Antropología Visual. Dialéctica de las imágenes y construcción del conocimiento. (Comps. E. Moreyra y M. Falabella). Rosario: Cátedra de Antropología Visual, Universidad Nacional de Rosario.

VV AA (2011). Disrupción social y boom documental cinematográfico: Argentina en los años 60 y 90. (Eds. I. Marrone y M. Moyano Walker). Buenos Aires: Biblos. 
VV AA (2011). Del documento a la ficción: la comunicación y sus fraudes. (Comps. G. Aprea y A. Campero). Buenos Aires: UNGS-Ediciones Imago Mundi.

VV AA (2012). Filmar la memoria: Los documentales audiovisuales y la re-construcción del pasado. (Ed. G. Aprea). Los Polvorines: Universidad Nacional de General Sarmiento.

VV AA (2014). Antropología e imagen. Pensar lo visual. (Coords. C. Guarini y M. G. De Angelis). Buenos Aires: Sans Soleil.

10.3 Bibliografía sobre Cine y Política

Amado, A. (2009). La imagen justa: cine argentino y política (1980- 2007). Buenos Aires: Colihue.

Aprea, G. (2008). Cine y politicas en Argentina. Continuidades y discontinuidades en 25 años de democracia. Buenos Aires: Universidad Nacional de General Sarmiento - Biblioteca Nacional.

Bettendorf, P. y Pérez Rial, A. (2014). Tránsitos de la mirada. Mujeres que hacen cine. Buenos Aires: Libraria.

Birri, F. (2008). La escuela documental de Santa Fe. Rosario: Prohistoria Ediciones.

Bracco, R. D. (2013). El cine político militante en Argentina (1966-1976). Buenos Aires: Libros en Red.

Burucúa, Constanza (2009). Confronting the Dirty War in Argentine Cinema, 1983-1993: Memory and Gender in Historical Representations. Woodbridge: Tamesis.

Bustos, G. (2006). Audiovisuales de combate. Acerca del videoactivismo contemporáneo. Buenos Aires: CCEBA/La Crujía.

De la Puente, M. y Russo, P. (2007). El compañero que lleva la cámara: cine militante argentino contemporáneo. Buenos Aires: Editorial Tierra del Sur.

Flores, S. (2013). El Nuevo Cine Latinoamericano y su dimensión continental: regionalismo e integración cinematográfica. Buenos Aires: Ediciones Imago Mundi.

Getino, O. (2005). Cine argentino: entre lo posible y lo deseable. Buenos Aires: Ciccus.

- (2006). El capital de la cultura: Las industrias culturales en Argentina y en la integración Mercosur. Buenos Aires: Honorable Senado de la Nación.

-- y Schargorodsky, H. (2008). El cine argentino en los mercados externos: Introducción a una problemática económica y cultural. Buenos Aires: Observatorio Cultural, Facultad de Ciencias Económicas, Universidad de Buenos Aires.

- y Velleggia, S. (2002). Cines de 'las historias de la revolución': Aproximación a las teorías y prácticas de 'intervención politica' en América Latina (1967-1977). Buenos Aires: Altamira.

Lopez Riera, E. (2009). Albertina Carri: el cine y la furia. Valencia: Generalitat Valenciana. 
Mestman, M. (2014). Estados Generales del Tercer Cine: los documentos de Montreal. ReHiMe: Cuadernos de la Red de Historia de los Medios 3, Buenos Aires.

Peña, F. M. (2003). El cine quema: Jorge Cedrón. Buenos Aires: Altamira.

-- y Vallina, C. (2000). El cine quema: Raymundo Gleyzer. Buenos Aires: Ediciones de la Flor.

Rangil, V. (2005). Otro punto de vista: mujer y cine en la Argentina. Rosario: Editorial Beatriz Viterbo.

Tal, T. (2005). Pantallas y revolución: una visión comparativa del Cine de Liberación y el Cinema Novo. Buenos Aires: Ediciones Lumiére - Universidad de Tel Aviv.

Visconti, J. L. (2015). El peligro está en los vivos. Representaciones y omisiones en el cine argentino 1976/1983. Temperley: Editorial Tren en Movimiento.

VV AA (2008). Otras historias de amor (Gays, lesbianas y travestis en el cine argentino). (Comp. A. Melo). Buenos Aires: Ediciones Lea.

VV AA (2009). Una historia del cine politico y social en Argentina: formas, estilos y registros (18961969). (Eds. A. L. Lusnich y P. Piedras). Buenos Aires: Nueva Librería.

VV AA (2011). Una historia del cine politico y social en Argentina: formas, estilos y registros (19692009). (Eds. A. L. Lusnich y P. Piedras). Buenos Aires: Nueva Librería.

VV AA (2012). Formas de la memoria. Notas sobre el documental argentino reciente. (Coord. G. D’Iorio, L. Galazzi y G. Lucero). Buenos Aires: IUNA Audiovisuales.

VV AA (2013). Masas, pueblo, multitud en el cine y televisión. (Eds. M. Mestman y M. Varela). Buenos Aires: Eudeba.

VV AA (2014). Cine y revolución en América Latina. (Eds. A. L. Lusnich, P. Piedras y S. Flores). Buenos Aires: Imago Mundi.

VV AA (2016). Las rupturas del 68 en el cine de América Latina. (Coord. M. Mestman). Madrid: Akal.

10.4 Bibliografía sobre Historia del cine argentino

Aguilar, G. y Jelicié, E. (2010). Borges va al cine. Buenos Aires: Libraria.

Bendazzi, G. (2008). Quirino Cristiani, pionero del cine de animación. Buenos Aires: Ediciones de la Flor.

Berardi, M. (2006). La vida imaginada: vida cotidiana y cine argentino, 1933-1970. Buenos Aires: Ediciones del Jilguero.

Borge, J. (2005). Avances de Hollywood: Crítica cinematográfica en Latinoamérica, 1915-1945. Rosario: Beatriz Viterbo Editora. 
Broitman, A. I. (2014). Aprender mirando. Los cineclubs y sus revistas como espacios de enseñanza-aprendizaje del cine en las décadas del 50 y 60. Toma Uno 3, Córdoba. Recuperado de https://revistas.unc.edu.ar/index.php/toma1/article/view/9306

Campodonico, R. H. (2005). Trincheras de celuloide. Bases para una historia político-económica del cine argentino. Madrid: Universidad de Alcalá.

Cuarterolo, A. (2013a). De la foto al fotograma. Relaciones entre cine y fotografias en la Argentina (18401933). Montevideo: CdF Ediciones.

-- (2013b) Introducción: Investigar sobre cine silente en Latinoamérica. Imagofagia 8, Buenos Aires.

http://www.asaeca.org/imagofagia/index.php/imagofagia/article/view/481

Fontana, P. (2009). Arlt va al cine. Buenos Aires: Libraria.

Gil Mariño, C. (2015). El mercado del deseo: tango, cine y cultura de masas en la Argentina de los '30. Buenos Aires: Teseo.

Gociol, J. e Invernizzi, H. (2006). Cine y dictadura: la censura al desnudo. Buenos Aires: Capital Intelectual.

Invernizzi, H. (2014). Cines rigurosamente vigilados. Censura peronista y antiperonista, 1946-1976. Buenos Aires: Capital Intelectual.

Karush, M. (2013). Cultura de clase. Radio y cine en la creación de una Argentina dividida (1920-1946). Buenos Aires: Ariel.

Kozak, D. (2013). La mirada cinéfila. La modernización de la crítica en la revista Tiempo de Cine. Mar del Plata: Festival Internacional de Cine de Mar del Plata.

Kriger, C. (2009). Cine y peronismo. El estado en escena. Buenos Aires: Siglo XXI.

-- (2014). Estudios sobre cine clásico en Argentina: de la perspectiva nacional a la comparada. AdVersuS XI, Buenos Aires, junio. Recuperado de http://www.adversus.org/indice/nro-26/dossier/XI2609.pdf

Levinson, A. (2011). Cine en el país del viento. Antártida y Patagonia en el cine argentino de los primeros tiempos. Viedma: Fondo Editorial Rionegrino.

Lusnich, A. L. (2007). El drama social-folklórico: el universo rural en el cine argentino. Buenos Aires: Biblos.

Maldonado, L. (2006). Surgimiento y configuración de la crítica cinematográfica en la prensa argentina (1896-1920). Buenos Aires: iRojo.

Mancini, A. (2014). Bioy Casares va al cine. Buenos Aires: Libraria.

Maranghello, C. (2005). Breve historia del cine argentino. Barcelona: Laertes. 
Marrone, I. (2003). Imágenes del mundo histórico: identidades y representaciones en el noticiero y el documental en el cine mudo argentino. Buenos Aires: Biblos.

Mateu, C. (2008). Avances y límites de la industria cinematográfica argentina, 1933-1955. Buenos Aires: Ediciones Cooperativas.

Méndez, P. y García Falco, M. C. (2010). Cines de Buenos Aires. Patrimonio del siglo XX. Buenos Aires: Cedodal.

Neveleff, J., Monforte, M. y Ponce de León, A. (2013). Historia del Festival Internacional de Cine de Mar del Plata. Volumen 1. Primera época: 1954-1970. De la epopeya a la resignación. Buenos Aires Corregidor.

- (2014). Historia del Festival Internacional de Cine de Mar del Plata. Volumen 2. Segunda época: 1996-2010. De los tacos altos a las zapatillas. Buenos Aires Corregidor.

Paz Leston, E. (2015). Victoria Ocampo va al cine. Buenos Aires: Libraria.

Peña, F. M. (2012). Cien años de cine. Buenos Aires: Biblos.

Pereira, M. M. (2015). La conservación del cine nacional: La larga agonía del patrimonio fílmico. Imagofagia 11, Buenos Aires, octubre. Recuperado de http://www.asaeca.org/imagofagia/index.php/imagofagia/article/view/7803

Posadas, A., Landro, M. y Speroni, M. (2005). Cine sonoro argentino 1933-1945. Buenos Aires: El Calafate.

Raggio, M. (2011). Leonardo Favio: cine argentino de antibéroes. Mendoza: Jaguel.

Ramírez Llorens, F. (2016). Noches de sano esparcimiento. Estado, católicos y empresarios en la censura al cine en Argentina, 1955-1973. Buenos Aires: Libraria.

Sorrentino, P. (2011). Cine argentino. Una historia, muchos relatos. Córdoba: Ferreyra Editor.

VV AA (2000). Cine argentino: industria y clasicismo, 1933-1956. (Dir. C. España). Buenos Aires: Fondo Nacional de las Artes.

VV AA (2000). El Grupo de los 5 y sus contemporáneos: pioneros del cine independiente en la Argentina: 1968-1975. (Comp. N. Tirri). Buenos Aires: Subsecretaría de Industrias Culturales, Secretaría de Cultura de la Ciudad de Buenos Aires.

VV AA (2003). Páginas de cine. (Dir. C. Kriger). Buenos Aires: Archivo General de la Nación. Maranghello, C. (2002). Artistas Argentinos Asociados: La epopeya trunca. Buenos Aires: Ediciones del Jilguero.

VV AA (2004). Cine argentino: modernidad y vanguardias, 1957-1983. (Dir. C. España). Buenos Aires: Fondo Nacional de las Artes.

VV AA (2010). ¿Qué he hecho yo para merecer esto? Guía para el investigador de medios audiovisuales en la Argentina. (Coord. G. Aguilar y S. Romano). Buenos Aires: Asaeca. 
VV AA (2013). 30-50-70: Conformación, crisis y renovación del cine industrial argentino y latinoamericano. (Comp. R. Manetti y L. Rodríguez Riva). Buenos Aires: Facultad de Filosofía y Letras, Universidad de Buenos Aires.

10.5 Bibliografía sobre Reflexiones teóricas del cine

Choi, D. (2009). Transiciones del cine. De la modernidad a la contemporaneidad. Buenos Aires: Santiago Arcos Editor.

Gutiérrez, E. (2010). Cine y percepción de lo real. Buenos Aires: Las Cuarenta.

Oubiña, D. (2008). Filmología. Ensayos con el cine. Buenos Aires: Manantial.

-- (2009). Una juguetería filosófica. Cine, cronofotografía y arte digital. Buenos Aires: Manantial.

- (2011). El silencio y sus bordes: modos de lo extremo en la literatura y el cine. Buenos Aires: Fondo de Cultura Económica.

Russo, E. (2008). El cine clásico. Itinerarios, variaciones y replanteos de una idea. Buenos Aires: Manantial.

Tassara, M. (2001). El castillo de Borgonio: la producción de sentido en el cine. Buenos Aires: Atuel.

Wolf, S. (2004). Cine-literatura: Ritos de pasajes. Buenos Aires: Paidós.

VV AA (2004). Pensar el Cine 1. Imagen, ética y filosofía. (Comp. G. Yoel). Buenos Aires: Manantial.

VV AA (2004). Pensar el Cine 2. Cuerpo(s), temporalidad y nuevas tecnologías. (Comp. G. Yoel). Buenos Aires: Manantial.

VV AA (2005). La verdad a 24 cuadros por segundo. Estudios sobre cine. (Ed. D. Parente). Mar del Plata: Suárez.

VV AA (2007). Cine y pensamiento: las charlas de Mar del Plata. Buenos Aires: Ediciones en Danza.

10.6 Bibliografía sobre lo Regional y lo Trasnacional

Brunetti, R. (2016). Cien años de cine en Tucumán. Tucumán: Ediciones del Parque.

Escobar, P. (2010). Cine e historia: La Patagonia en imágenes (1930-1976). Trelew: Jornada.

Etchenique, J. y C. Pena (2003). Apuntes para una historia del cine en el Territorio Nacional de La Pampa. Santa Rosa: Departamento de Investigaciones Culturales, Subsecretaría de Cultura, Ministerio de Cultura y Educación, Gobierno de La Pampa.

Greco, D. (2012). Proyectando ilusiones. La historia de los cines de Rosario y su gente. Rosario: Editorial Cuenta Conmigo. 
Guiamet, R. (2012). Cine silente vs. Cine mudo: el primitivo cine gauchesco santafesino. Rosario: Ciudad Gótica.

Moguillansky, M. (2016). Cines del sur: la integración cinematográfica entre los paises del Mercosur. Buenos Aires: Imago Mundi.

Neifert, A. (2007). El cine en Bahia Blanca. Memoria y homenaje. Bahía Blanca: s/d.

Neveleff, J. (2007). Mar del Plata en el ojo del cine. Mar del Plata: Secretaría de Cultura.

Saenz, S. (2004). El cine en Córdoba: Catálogo de la producción cinematográfica 1915-2000. Córdoba: Ferreyra Editor.

Scaglia, A. y Varea, F. (2008). Rosarinos en pantalla. Rosario: Cineclub Rosario-CEPIC.

Viaro, R. (2013). Aquellos cines de Mar del Plata: Historia gráfica de los cinematógrafos. Mar del Plata: Asociación Amigos Archivo Histórico Municipal Museo Villa Mitre.

VV AA (2002). Política, universidad y medios: Contribución al estudio de las condiciones de producción de noticias de Canal 10 de Córdoba en los '60 y '70. (Coord. S. Romano). Córdoba: Ferreyra Editor.

VV AA (2008). Hacer cine. Producción visual en América Latina. (Comp. E. Russo). Buenos Aires: Paidós.

VV AA (2011). Imágenes compartidas. Cine argentino - Cine español. Buenos Aires: Centro Cultural de España en Buenos Aires.

VV AA (2014). La pantalla desbordada: Ensayos sobre prácticas y discursos en torno al cine independiente. (Comp. I. Dobree). Buenos Aires: Ed. Grupo Cine Cipolletti.

VV AA (2016). Pantallas trasnacionales. Intercambios y relaciones identitarias entre el cine argentino y mexicano del período clásico. (Eds. A. L. Lusnich, A. Cuarterolo y S. Flores). Buenos Aires: Imago Mundi.

10.7 Bibliografía sobre el Audiovisual

Alonso, R. y Taquini, G. (1999). Buenos Aires Video X. Diez años de video en Buenos Aires. Buenos Aires: Instituto de Cooperación Iberoamericana.

Carlón, M. (2006). De lo cinematográfico a lo televisivo: Metatelevisión, lenguaje y temporalidad. Buenos Aires: La Crujía.

- (2016). Después del fin. Una perspectiva no antropocéntrica sobre la post-tv, el post-cine y YouTube. Buenos Aires: La Crujía.

Garavelli, C. (2014). Video experimental argentino contemporáneo. Una cartografía crítica. Sáenz Peña: Universidad Nacional de Tres de Febrero.

La Ferla, J. (2009). Cine (y) digital: aproximaciones a posibles convergencias entre el cinematógrafo y la computadora. Buenos Aires: Manantial. 
Molfetta, A. (2013). Videoarte en Buenos Aires (1966-1993). Buenos Aires: Teseo.

Varela, M. (2010). La televisión: el espacio vacío de la crítica. Imagofagia 2, Buenos Aires, octubre. Recuperado

http://www.asaeca.org/imagofagia/index.php/imagofagia/article/view/795

de

VV AA (2008). Historia crítica del video argentino. (Ed. J. La Ferla). Buenos Aires: MALBAFundación Telefónica.

VV AA (2011). Recorridos. Del formato analógico al digital en el campo audiovisual. (Comp. S. Sel, S. Pérez Fernández y S. Armand). Buenos Aires: Prometeo - Facultad de Ciencias Sociales, Universidad de Buenos Aires.

VV AA (2012). Territorios audiovisuales: cine, video, televisión, instalación, documental, nuevas tecnologías, paisajes mediáticos. (Comps. J. La Ferla y S. Reynal). Buenos Aires: Libraria.

VV AA (2015). Poéticas del movimiento. Aproximaciones al cine y video experimental argentino. (Eds. C. Garavelli y A. Torres). Buenos Aires: Libraria.

10.8 Bibliografía sobre los Estudios de Cine en Argentina

Ciancio, M. B. (2013). Estudios sobre cine en Argentina. Consideraciones epistemológicas y metodológicas. Nuevo Mundo Mundos Nuevos, diciembre. Recuperado de http://nuevomundo.revues.org/66138

Molfetta, A. (2010). De la interdisciplina al impacto social, dos puntos clave de discusión para nuestra área. Imagofagia 2, Buenos Aires, octubre. Recuperado de http://www.asaeca.org/imagofagia/index.php/imagofagia/article/view/785

10.9 Filmografía de Documentales sobre Cine

Historia del documental argentino (Leandro Polverino, 2001)

La noche de las cámaras despiertas (Hernán Andrade y Víctor Cruz, 2002)

Raymundo (Ernesto Ardito y Virna Molina, 2003)

Cinéfilos a la intemperie (Carlos O. García y Alfredo Salvutzky, 2005)

Dirigido por... (Rodolfo Durán, 2005)

Donde comienza el camino (Hugo Grosso, 2005)

La película de Niní (Raúl Etchelet, 2005)

Meykinof (Carmen Guarini, 2005)

Nadie inquietó más - Narciso Ibáñez Menta (Gustavo Mendoza, 2005)

Carne sobre carne (Diego Curubeto, 2008) 
La mirada febril (Rafael Filipelli, 2008)

Fragmentos rebelados (David Blaustein, 2009)

Alfredo Ligotti, una pasión cinéfila (Roberto Ángel Gómez, 2010)

Cine, dioses y billetes (Lucas Brunetto, 2010)

Huellas y memoria de Jorge Prelorán (Fermín Álvarez Rivera y Emiliano Penelas, 2010)

Metrópolis refundada (Evangelina Loguercio, Diego Panich, Laura Tusi y Sebastián Yablon, 2010)

Ricardo Becher, recta final (Tomás Lipgot, 2010)

Una película de gente que mira películas (Fernando Arditi y Javier Pistani, 2012)

Narcisa (Daniela Muttis, 2014)

Reflejo Narcisa (Silvina Szperling, 2014)

BirriLata, una vuelta en tren (Lorena Yenni, 2015)

Canción perdida en la nieva (Francisco D’Eufemia, 2015)

El teorema de Santiago (Ignacio Masllorens y Estanislao Buisel, 2015)

Sin dejar rastro (Diego Kartaszewicz y Roberta Sánchez)

Un importante preestreno (Santiago Calori, 2015)

Audaz se eleva (Lisandro Leiva y Mariano Torres, 2016)

Favio: Crónica de un director (Alejandro Venturini, 2016)

\section{Notas}

1. La aparición recientemente de Revista de cine, dirigida por Rafael Fillippelli, apunta a crear otro espacio similar para la discusión y reflexión crítica, con la colaboración de críticos, realizadores y académicos como David Oubiña, Sergio Wolf y Juan Villegas.

2. Ambas revistas plantean en sus editoriales iniciales la necesidad de un ámbito propio donde tanto el cine documental como el cine silente puedan ser comprendidos en su complejidad y especificidades a diferencia de las miradas más generalistas que suelen primar en otras publicaciones.

3. En la versión revisada del libro, publicada en 2010, Aguilar reconoce en el prólogo su lugar pionero, destacando la proliferación bibliográfica dedicada al Nuevo Cine Argentino desde su publicación. 
4. Más allá del caso específico del NCA, Octavio Getino (2005, 2006, 2008) dedicó su trabajo en estos años a investigar sobre las condiciones económicas e industriales de la producción fílmica argentina contemporánea. En los últimos años se puede destacar asimismo el proyecto coordinado por José Borello en la Universidad Nacional de General Sarmiento dedicado a la producción, circulación y consumo de cine en Argentina.

5. Surgen en este sentido bibliografía que se pregunta por otras áreas del cine nacional contemporáneo, en sintonía con los postulados de Aguilar en el prólogo revisado de 2010, donde se refiere al 'cine anómalo', una producción al margen de las instituciones que se va fortaleciendo en esos años. Son relevantes en este sentido publicaciones como el libro colectivo Cines al margen (2007) donde se aborda desde la ciencia ficción de Fernando Spiner y Gustavo Mosquera a las modalidades alternativas de Aldo Paparella y Esteban Sapir. En una línea similar, Carina Rodríguez (2014) estudia el cine de terror nacional considerando no sólo sus películas, sino también los circuitos de producción y exhibición en que se desarrolla.

6. Dentro de los cineastas estudiados por Margulis se destaca la producción de la productora Cine Ojo, una de cuyas fundadoras, Carmen Guarini, es al mismo tiempo una de las principales referentes del campo de la Antropología Visual. Así como el NCA implicaba un marcado diálogo con el campo de la crítica, en el documental la presencia de los cineastas en el terreno de la reflexión es recurrente.

7. La propuesta de Zylberman implica la introducción de nuevos factores a los estudios de la memoria más allá del acto de recordar y la ética de lo testimoniable. En esa sintonía, también Clara Garavelli (2014) propone considerar otras dimensiones implicadas en la recuperación del pasado al estudiar el video experimental que, retomando el concepto de John Grierson, postula un 'tratamiento creativo de la realidad' para reconfigurar el pasado traumático.

8. La reflexión sobre la memoria y la representación del pasado ha motivado investigaciones que trascienden al documental, como los libros de Alejandra Rodríguez $(2009,2015)$ o el dossier temática del $\mathrm{N}^{\circ} 4$ de la Revista Toma Uno dedicado a Cine e Historia.

9. La dimensión internacional se halla presente asimismo en la compilación que dirige Mestman con Mirta Varela, Masas, pueblo, multitud en el cine y la televisión (2013). Allí no sólo se abren de los límites de lo nacional sino que también proponen una mirada transmedial al incorporar los discursos televisivos a la reflexión académica.

10. Amado es, al mismo tiempo, integrante y parte del grupo inicial del Instituto Interdisciplinario de Estudios de Género de la Facultad de Filosofía y Letras de la Universidad de Buenos Aires, espacio de importante producción en torno a este campo.

11. Aunque en menor medida, los estudios de masculinidad también han comenzado a ser objeto de interés de distintos investigadores. Un acercamiento a ello se puede encontrar en el Dossier coordinado por Dorian Lugo Beltrán en Imagofagia $\mathrm{N}^{\circ} 11$, donde se revisa esta tradición y se la propone como perspectiva analítica para el cine latinoamericano.

12. Como ayuda al investigador en el marco de este panorama de archivos, ASAECA publicó en 2010 un libro, ¿Qué he hecho yo para merecer esto?, donde se presentó un relevamiento de acervos audiovisuales en Argentina, ofreciendo un análisis de su estado y su accesibilidad. 
13. Desde fuera de Argentina, el italiano Giannalberto Bendazzi (2008) ha trabajado sobre la figura Quirino Cristiani, pionero del cine de animación a nivel global.

14. Cruzando estos enfoques centrados en la representación, Mario Berardi (2006) propuso un análisis de los imaginarios construidos por el cine clásico, retomando las propuestas de Pierre Sorlin y Marc Ferro.

15. Resulta paradójico que, así como el cine silente ha sido escasamente abordado hasta estos últimos años, su crítica sí ha sido objeto de diversos libros como los de Jason Borge (2005) y Leonardo Maldonado (2006), donde, sin embargo, resulta secundario a un análisis literario e intelectual.

16. Ramírez Llorens también ha dirigido dentro de la Red de Historia de los Medios (ReHiMe) del Instituto Gino Germani de la Facultad de Ciencias Sociales (UBA), la construcción de una base de datos de estrenos cinematográficos entre las décadas de 1950 y 1980, sistematizando una gran conjunto de fuentes dispersas en pos de promover nuevos abordajes a la historia de la exhibición cinematográfica.

17. El impacto del Mercosur en la producción cinematográfica fue también un tema abordado por Octavio Getino (2006) desde la perspectiva de las Industrias Culturales, proponiendo un seguimiento del desarrollo de las acciones llevadas a cabo por los entes públicos y las empresas privadas.

18. Ha sido de gran importancia en estas dinámicas el desarrollo de iniciativas como la Red de Investigadores de Cine Latinoamericano (RICiLa), que han fomentado la circulación e intercambio de conocimientos entre investigadores iberoamericanos.

19. En los últimos años las políticas de descentralización de la producción y la renovación tecnológica llevaron a la proliferación de instancias de producción audiovisual a lo largo de todo el territorio nacional, generando una cartografía heterogénea de producciones que están llevando a plantear nuevos interrogantes y marcos teóricos.

20. Un lugar aún indeterminado en este campo es el que ocupa la televisión. Si bien la tendencia hacia los estudios del audiovisual implicaría incorporarla dentro de los objetos de estudio, cuestiones metodológicas, críticas y teóricas hacen que siga siendo un terreno con pocas intersecciones con los estudios de cine. Mirta Varela (2010) señala que tanto la historia de su producción como de su legitimación en el ámbito cultural han llevado a que primen visiones sociológicas y semióticas en su estudio que la han separado del campo fílmico. 